\title{
How Liable Should a Lender Be? The Case of Judgment-Proof Firms and Environmental Risk: Comment
}

\author{
By Tracy R. Lewis and David E. M. Sappington*
}

In a previously published article in this $R e$ view, Rohan Pitchford (1995) develops an interesting model of lender liability and derives an intriguing finding. He shows that when lenders are held liable for the social damages that arise from the activities of a judgment-proof producer, expected social damages may increase, not decrease. ${ }^{l}$ This finding is important, in part because it would seem to cast doubt on the wisdom of recent legislation like CERCLA, which extends liability for environmental damages to certain creditors of the producers that cause the damages. ${ }^{2}$

Pitchford proves this finding using the standard model in the literature in which the damage technology is binary: either a known, fixed damage occurs or no damage occurs. In this setting, the lender who is made liable for social damages suffers a financial loss when damages occur. Consequently, she will only agree to finance the producer's project if she is promised a compensating financial gain when no damage occurs. But the larger the payment the producer

* Department of Economics, University of Florida, Gainesville, FL 32611 . We thank many colleagues for helpful comments, including Richard Carson, Christopher Garmon, Daniel Ingberman, Jennifer Reinganum, Alison Watts, Ralph Winter, and seminar participants at the University of Califomia-San Diego, the University of Southern California, and Washington University-St. Louis. The useful comments of anonymous referees are also gratefully acknowledged.

${ }^{1}$ See, in particular, property (ii) of Proposition 2 in Pitchford (1995 p. 1177). A producer is judgment-proof when the social damages that arise from his activities exceed his assets. When a producer is judgment-proof, he may have inadequate incentive to avoid social damages, since he cannot be forced to bear the full financial consequences of his activities. See Steven Shavell (1986, 1987) for a useful assessment of the judgment-proof problem.

${ }^{2}$ CERCLA refers to the Comprehensive Environmental Response, Compensation and Liability Act of 1980 . For a discussion of CERCLA and its interpretation by the courts, see Lewis Barr (1990) and Kurt Strasser and Denise Rodosevich (1993), for example. is required to make to the lender when no accident occurs, the less incentive the producer has to avoid an accident. Consequently, in this binary setting, lender liability generally does not enhance social welfare by reducing expected damages.

While a binary-damage technology is often useful for pedagogical purposes, it is seldom an accurate description of reality. In practice, production activities can usually give rise to many different levels of social damages. Therefore, it is important to determine whether the qualitative conclusions that arise in the binary setting persist more generally. In the present instance, they do not always do so. When many values of social damages are possible, the deep pockets of a lender can often be employed to mitigate judgment-proof problems in the following manner. The lender is asked to deliver some funds to the producer. The producer is relieved of any obligation to repay this loan if realized damages are sufficiently small. Then, to ensure that the transaction is profitable for the lender, the solvent producer is required to repay more than the full value of the loan when moderately large damage realizations occur. When the largest possible damages occur, the producer must employ all of his own initial assets and the funds provided by the lender to compensate victims for the damages they suffer.

We present plausible conditions under which this payment structure can simultaneously achieve the two goals that are fundamentally incompatible when damage realizations are binary: enhance the producer's incentive to limit social damages and ensure a normal profit for the lender. We show that, whatever their magnitude, a lender's resources will be strictly valuable in mitigating the judgment-proof problem if the initial assets of the judgment-proof producer are sufficiently pronounced. We also point out that if the lender's resources (or "deep pockets") are sufficiently pronounced, then they can serve to mitigate the judgment-proof prob- 
lem regardless of how small the producer's initial assets may be.

Our analysis proceeds as follows. We first summarize the key elements of our model (which parallels Pitchford's [1995] model) in Section I. Then we present and explain our main findings in Section II. Our analysis concludes in Section III with a brief discussion of alternative settings in which lenders' deep pockets can help to mitigate judgment-proof problems even more generally.

\section{Elements of the Model}

There are two risk-neutral actors in the model: a producer and a lender. The producer's activity generates a known, fixed level of private profit, $V>0$. It also gives rise to social damages, $D$, which are stochastic, and can take on any value in the interval $[0, \bar{D}]$. The producer can undertake an unobservable activity, called care $(c)$, to limit social damages. Increased care by the producer systematically reduces the likelihood of large social damages and increases the likelihood of small damages, and does so at a decreasing rate. ${ }^{3}$ Formally, letting $f(D \mid c)$ and $F(D \mid c)$, respectively, denote the density and distribution function of damages $D$ when the producer has provided care level $c,{ }^{4}$ we assume that for all $D \in[0, \bar{D}]:$ (1) $f\left(D \mid c_{2}\right) / f\left(D \mid c_{1}\right)$ is strictly decreasing in $D$ for any $c_{2}>c_{1} \geq 0 ;^{5}$ and (2) $F_{c c}(D \mid c) \leq 0$ for all $c \geq 0$.

Care is costly for the producer to deliver. We will denote by $K(c)$ the monetary value of the disutility that the producer incurs when he delivers care level $c$. Care is supplied with in-

\footnotetext{
${ }^{3}$ In Pitchford's (1995) model, the producer chooses the (unobservable) probability that an accident will occur. If an accident occurs, it imposes a fixed, known level of social damages. Thus, our model would correspond exactly to Pitchford's model if $D$ could take on one of only two values 0 and, say, $\bar{D}$, and if $c \in[0,1]$ were the probability that $D=0$.

${ }^{4} f(D \mid c)>0$ for all $D \in[0, \bar{D}]$ and for all $c \geq 0$, and $f(\cdot)$ is twice continuously differentiable.

${ }^{5}$ This assumption states that $f(D \mid c)$ satisfies the monotone likelihood ratio property (Paul R. Milgrom, 1981), which ensures that greater care renders the smaller damage levels more likely in the sense of first-order stochastic dominance [i.e., $F_{c}(D \mid c) \geq 0$ for all $D$ ]. The assumption also implies that $f_{c}(D \mid c) / f(D \mid c)$ decreases as $D$ increases.
}

creasing marginal cost, so $K^{\prime}(c)>0$ and $K^{\prime \prime}(c)>0$ for all $c \geq 0$.

The level of care that the producer delivers is unobservable. Its magnitude is governed by the financial rewards and penalties that the producer faces. We assume that a compensatory-damage policy is imposed, since this is the policy under which Pitchford (1995) finds no role for a lender's deep pockets. ${ }^{6}$ Under a compensatorydamage policy, the solvent producer must compensate victims exactly for the damages they suffer. Formally, letting $P(D)$ denote the payment that the producer must make to victims when damages $D$ occur, a compensatorydamage policy (CDP) is implemented when $P(D)=D$ for all $D \in[0, A]$, where $A$ denotes the producer's financial assets.

Because a CDP holds a producer financially responsible for the full social costs of his activities only if realized social damages do not exceed his assets, a CDP will not induce a producer to deliver the level of care that maximizes total expected social surplus $\left(c^{*}=\right.$ $\left.\operatorname{argmax}_{c}\left\{V-\int_{0}^{\bar{D}} D d F(D \mid c)-K(c)\right\}\right)$ if his financial assets are less than the maximum potential social damage from his activities $(\bar{D})$, as we assume throughout. The producer's assets are the sum of his initial wealth $(W \geq 0)$, his operating profit $(V>0)$, and any loan $(L \geq 0)$ he receives from the lender. The lender is assumed to have $\bar{L}>0$ dollars at her disposal. She can lend any portion of this amount to the producer if she finds it profitable to do so. The lender's expected profit when she delivers $L$ dollars to the producer is $\int_{0}^{\bar{D}} R(D) d F(D \mid c)-$ $L$, where $R(D) \geq 0$ is the payment the producer must make to the lender when damage level $D$ occurs. The lender's opportunity profit, like that of the producer, is normalized to zero. ${ }^{7}$

We seek to determine when the lender's resources can be used to enhance total expected surplus by increasing the level of care that the

\footnotetext{
${ }^{6}$ See property (ii) of Proposition 2 in Pitchford (1995 p 1177). Pitchford also provides useful analyses of alternative compensation rules.

7 Our central finding is not altered if the lender's opportunity cost of each dollar loaned to the producer is $1+r$ dollars, provided $r \geq 0$ is not too large. We, like Pitchford (1995), abstract from any market power the lender might exercise. See Dieter Balkenborg (2001) for an alternative approach
} 
producer undertakes to limit social damages. Formally, we ask when $L$ will be strictly positive at the solution to the following problem, labeled $[P]$.

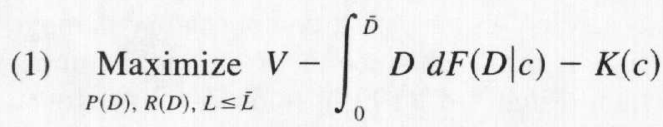

subject to:

$$
\begin{aligned}
\pi(c) \equiv & \int_{0}^{\bar{D}}[W+V+L-P(D) \\
& -R(D)] d F(D \mid c)-K(c) \\
\geq & W
\end{aligned}
$$

where

$$
\begin{array}{r}
c \in \underset{c^{\prime}}{\operatorname{argmax}} \pi\left(c^{\prime}\right) \\
P(D)+R(D) \leq W+V+L
\end{array}
$$$$
\text { for all } D \in[0, \bar{D}] \text {; }
$$

and

$$
\int_{0}^{\bar{D}} R(D) d F(D \mid c)-L \geq 0 .
$$

Expression (1) reflects the goal of maximizing total expected surplus, which is the net return from production $(V-K(c))$ less expected social damages. ${ }^{8}$ Expression (2) ensures that the producer's expected net return is no less than his wealth which, by assumption, is the

\footnotetext{
${ }^{8} \mathrm{We}$ assume that total expected surplus is strictly positive at the solution to $[P]$.
}

most he can secure from alternative activities. The producer's expected net return is the difference between: (1) the sum of his wealth $(W)$, his operating profit $(V)$, and the funds $(L)$ he receives from the lender; and (2) the sum of his expected payments to victims $(P(\cdot))$ and the lender $(R(\cdot))$ and his cost of delivering care $(K(\cdot))$. Expression (3) reflects the compensatory-damage policy that is imposed, which requires the producer to compensate victims fully for the damages he causes whenever he has sufficient resources to do so, and to deliver all of his assets to victims when realized damages exceed his assets. ${ }^{9}$ Expression (4) states that the producer will deliver the level of care that maximizes his expected net return, taking as given the payments he must make to victims and the lender. Care is assumed to be sufficiently effective in reducing social damages relative to its cost that a strictly positive level of care is always induced. ${ }^{10}$ Furthermore, we focus on settings where the unobservability of the producer's care is constraining, so additional care would increase total surplus at the solution to $[P] .{ }^{11}$ Expression (5) ensures that the total payments made by the producer do not exceed his assets. ${ }^{12}$ Expression (6) guarantees that the pro-

\footnotetext{
${ }^{9}$ A compensatory-damage policy (CDP) is not the policy that maximizes total expected surplus, subject to constraints (2) and (4)-(6). (See Lewis and Sappington, 1999.) However, a society may prefer a CDP to the surplus-maximizing policy if the society values sufficiently highly the fact that the producer compensates victims fully for the damages he causes whenever he is able to do so.

${ }^{10}$ This will be the case in our model if limit ${ }_{c \rightarrow 0} K^{\prime}(c)=$ 0 , for example. In solving $[P]$, we replace expression (4) with the requirement that $\left.\pi^{\prime}(\tilde{c})\right|_{\tilde{c}=c}=0$, thereby assuming that the "first-order approach" is valid. William P. Rogerson (1985) proves that the first-order approach is valid when the counterparts to the assumptions maintained here hold in a setting where the distribution of the outcome $(D)$ is discrete, rather than continuous.

${ }^{11}$ If the unobservability of care $(c)$ is not constraining, then $L$ must be strictly positive at the solution to $[P]$, since $W+V<\bar{D}$. Consequently, our focus on settings where the unobservability of $c$ is constraining does not affect our main finding that a lender's deep pockets can increase surplus.

${ }^{12}$ Pitchford (1995) admits the possibility that the producer cannot be compelled to forfeit all of his wealth. Pitchford also assumes that the production activity requires an initial investment $(K>0)$. These differences between our models do not affect the central contrast between the predictions of our models. In particular, the variables in our model are readily reinterpreted to allow for a required initial
} 
ducer's expected payments to the lender are at least as large as the loan $(L)$ he receives, thereby ensuring the voluntary participation of the lender.

\section{The Value of Deep Pockets}

We wish to determine whether the lender's deep pockets can help to mitigate the judgmentproof problem. Proposition 1 provides a sufficient condition for this to be the case. Proposition 1 introduces two terms that require definition. First, $\tilde{c}$ denotes the level of care the producer will deliver under a compensatorydamage policy when he receives no loan from and makes no payments to the lender. Formally, $\left(\tilde{c}=\operatorname{argmax}_{c}\left\{\int_{0}^{W+V}[W+V-D] d F(D \mid c)-\right.\right.$ $K(c)\}$. Second, $\tilde{D}$ denotes the damage realization that forms the boundary between the smaller damages $(D \in[0, \tilde{D}))$ that become proportionately more likely and the larger damages $(D \in(\tilde{D}, \bar{D}])$ that become proportionately less likely as the producer increases his care above $\tilde{c}$. Formally, $\tilde{D}$ is defined by $f_{c}(\tilde{D} \mid \tilde{c})=0$.

PROPOSITION 1: Whatever their magnitude, a lender's deep pockets $(\bar{L}>0)$ help to mitigate the judgment-proof problem whenever the producer's initial assets $(W+V<\bar{D})$ are sufficiently large. (Formally, $L>0$ at the solution to $[P]$ if $W+V>\tilde{D}$.)

Proposition 1 reveals a sense in which the lender's assets and those of the producer are complements rather than substitutes in mitigating judgment-proof problems. Regardless of their magnitude, the lender's resources can always help to secure greater care from the producer, and thereby increase total surplus, if the producer's initial assets are sufficiently pronounced. However, the same may not be true if the producer's assets are meager.

To understand these conclusions, consider how the lender's resources $(\bar{L})$ are optimally

investment. When the investment exceeds the producer's wealth, a critical financing role for the lender arises, in addition to the motivational role on which we focus for expositional simplicity. employed when they can mitigate the judgmentproof problem. As Figure 1 illustrates, the lender's resources are employed to increase the producer's payoff (from $W+V-D$ to $W+$ $V+\bar{L}-D$ ) for the lowest damage realizations and to reduce the producer's payoff (from $W+$ $V-D$ to 0$)$ for an intermediate range of damages over which the producer would be solvent absent the lender's deep pockets. Increasing the producer's payoff for the lowest damage realizations $\left(D \in\left[0, D^{c}\right]\right.$ in Figure 1) provides enhanced incentives for care. Reducing the producer's payoff for intermediate damage realizations $\left[D \in\left(D^{c}, W+V\right)\right.$ in Figure 1] can also enhance incentives for care if these intermediate damage realizations are relatively large, and so become less likely as the producer delivers more care. These intermediate damage realizations will be relatively large when the producer's initial assets $(W+V)$ are large. As Proposition 1 indicates, a sufficient condition is that these assets exceed $\tilde{D}$. Therefore, when $W+V$ is sufficiently large, the use of deep pockets serves unambiguously to increase the producer's incentive to deliver care.

When the producer's initial assets are smaller (e.g., less than $\tilde{D}$ ) and when the lender's resources $(\bar{L})$ are also limited (e.g., sufficiently close to zero), it may not be possible to employ the lender's resources to induce

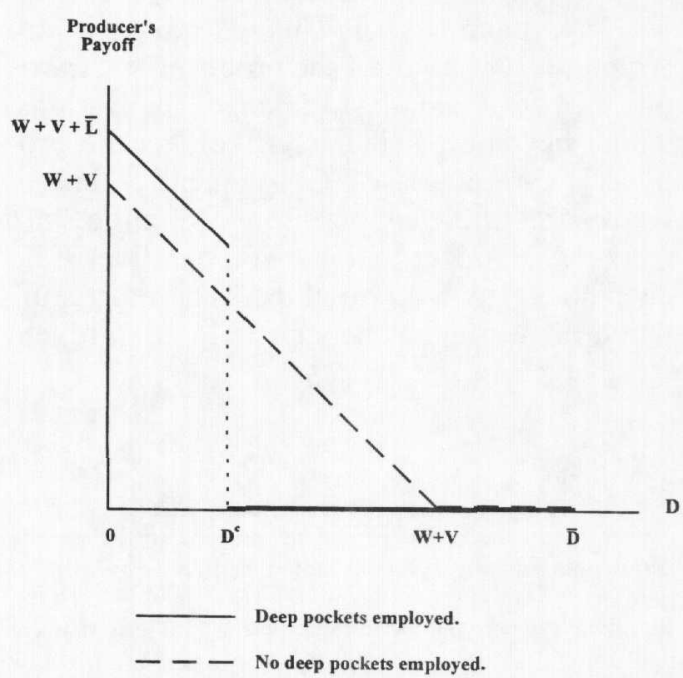

Figure 1. Producer's Payoff With and Without Deep POCKETS 
greater care from the producer. When $W+V$ is small, the intermediate damage realizations $\left[D \in\left(D^{c}, W+V\right)\right.$ in Figure 1] for which the producer will be required to repay any loan he receives will consist of relatively small values of $D$. Consequently, these damage realizations may become more likely as the producer increases care above the level that he would deliver in the absence of deep pockets. If this is the case, then the reduction in the producer's payoff (from $W+V-D$ to 0 ) that the use of deep pockets entails over this range will diminish the producer's incentive to take care. This deleterious effect may outweigh the associated beneficial effect of raising the producer's payoff for the smaller $D$ realizations. Consequently, it may not be possible to employ limited lender resources to induce greater care from a producer with meager initial assets. ${ }^{13}$

In contrast, if the lender's resources $(\bar{L})$ are sufficiently pronounced, they can often be employed to induce greater care from the producer even when the producer's initial assets $(W+V)$ are small. When $\bar{L}$ is large relative to $W+V$, the producer will be required to use all of his initial assets to repay the loan $(\bar{L})$ he receives for all but the very smallest damage realizations. Thus, the producer's payoff will be $W+V+\bar{L}$ if damages are extremely small and zero otherwise. (In Figure $1, W+V+\bar{L}$ will be large and $D^{c}$ will approach zero.) This extreme reward structure focuses all of the producer's rewards on the very smallest damage realizations, which become particularly likely as the producer's care increases. Consequently, this reward structure can often induce more care from the producer than he would deliver if no deep pockets were available. ${ }^{14}$ Therefore, sufficiently deep pockets can help to mitigate

\footnotetext{
${ }^{13}$ The logic here parallels the insights offered by Pitchford (1995).

${ }^{14}$ In particular, it can be shown that when $\bar{L}$ is sufficiently large, the producer can be induced to deliver the surplus-maximizing level of care $\left(c^{*}\right)$ if $K^{\prime}\left(c^{*}\right) f\left(0 \mid c^{*}\right)$ / $f_{c}\left(0 \mid c^{*}\right) \leq \int_{0}^{\bar{D}}[V+W-D] d F\left(D \mid c^{*}\right)-K\left(c^{*}\right)$. Intuitively, when the likelihood of the smallest damage realization decreases sufficiently rapidly as care falls below $c^{*}$ [so $f_{c}\left(0 \mid c^{*}\right) / f\left(0 \mid c^{*}\right)$ is large], the producer can be induced to deliver $c^{*}$ when the lender's deep pockets are sufficiently pronounced.
}

judgment-proof problems even when the producer's initial assets are meager.

\section{Conclusions}

We have shown that Pitchford's important observation that the deep pockets of lenders do not help to resolve judgment-proof problems may require modification when social damages can take on more than two values. In particular, we have shown that deep pockets of any magnitude can help to mitigate the judgment-proof problem if the producer's initial assets are sufficiently large, and that sufficiently deep pockets can serve this role more generally.

In closing, we mention two variations on the present model that give rise to an expanded role for the deep pockets of lenders. ${ }^{15}$ First, lenders may be especially skilled at monitoring the producer's efforts to avoid social damages. ${ }^{16}$ When this is the case, a lender can be induced to employ her special skills to reduce equilibrium expected damages by holding her liable for realized damages. Second, a compensatory-damage policy may not be imposed. For instance, society may only require that victims be compensated for expected damages, not actual damages. In this case, the deep pockets of a lender can always be employed to mitigate judgment-proof problems. The greater flexibility in payment structures that arises when a compensatory-damage policy is not imposed enables the lender's resources to always be employed to create stronger incentives for the producer to avoid social damages. ${ }^{17}$

\section{APPENDIX}

A sketch of the proof of Proposition 1 follows. The complete proof is available upon request from the authors.

The proof begins by constructing the Lagrangean function associated with $[P]$, and differentiating this function to derive the necessary

\footnotetext{
${ }^{15}$ See Balkenborg (2001) for a third variation: more pronounced lender bargaining power.

${ }^{16}$ See Shavell (1987) and Marcel Boyer and JeanJacques Laffont (1997) for related analyses in which the lender can monitor the producer's activities perfectly and costlessly.

${ }^{17}$ See Lewis and Sappington (1999).
} 
conditions for a solution to $[P]$. These conditions are employed in a proof by contradiction which reveals that the Lagrange multiplier associated with constraint (4) is strictly positive at the solution to $[P]$, so total expected surplus would increase if the producer were to deliver more care. This fact is then employed to show that at the solution to $[P]$ :

(A1) $R(D)$

$$
=\left\{\begin{array}{lc}
0 & \text { for all } D \in[0, \hat{D}(L)] \\
W+V+L-D & \text { for all } D \in(\hat{D}(L), \\
& W+V+L]
\end{array}\right.
$$

for some $\hat{D}(L) \in[0, W+V+L]$. Therefore, the solution to $[P]$ is characterized in part by the following equalities:

$$
\begin{aligned}
H^{1} \equiv & \int_{0}^{\hat{D}(L)}[W+V+L-D] f_{c}(D \mid c) d D \\
& -K^{\prime}(c) \\
= & 0
\end{aligned}
$$

and

$$
\begin{aligned}
H^{2} \equiv & \int_{\hat{D}(L)}^{W+V+L}[W+V+L-D] d F(D \mid c) \\
& -L \\
= & 0
\end{aligned}
$$

Equality (A2) reflects the producer's profitmaximizing choice of $c$, given the repayment policy summarized in (A1). Equality (A3) reflects constraint $(6)$ in $[P]$.

Letting $H_{j}^{i}$ denote the partial derivative of $H^{i}$ with respect to variable $j \in\{c, L, \hat{D}\}$, it follows from (A2), (A3), and Cramer's Rule that:

$$
\frac{d c}{d L}=\frac{\left|\begin{array}{cc}
-H_{L}^{1} & H_{\hat{D}}^{1} \\
-H_{L}^{2} & H_{\hat{D}}^{2}
\end{array}\right|}{\left|\begin{array}{ll}
H_{c}^{1} & H_{\hat{D}}^{1} \\
H_{c}^{2} & H_{\hat{D}}^{2}
\end{array}\right|}
$$

Define $\tilde{D}$ to be the damage realization for which $f_{c}(\tilde{D} \mid c)=0$ at the solution to the problem corresponding to $[P]$ where $L$ is restricted to be zero. If $W+V \geq \tilde{D}$, then, by raising $L$ above zero, it is possible to: (1) induce the producer to increase $c$ without altering his expected profit; and (2) ensure the lender's voluntary participation. These two outcomes, which secure an increase in surplus, are effected by reducing the producer's payoff for some realizations of $D$ for which $f_{c}(D \mid c)<0$ and by increasing the producer's payoff for some realizations of $D$ for which $f_{c}(D \mid c)>0$. Consequently, $(d c /$ $d L)\left.\right|_{L=0}>0$ and $L>0$ at the solution to [P] if $V+W \geq \tilde{D}$.

Now suppose $V+W<\tilde{D}$. Notice that when $L>0$ at the solution to $[P],(\mathrm{A} 1)$ implies that constraint $(6)$ in $[P]$ will only be satisfied if:

$$
\hat{D}(L)<W+V+L
$$

Differentiation of (A2) and (A3) reveals that the denominator of the fraction to the right of the equality in (A4) has the same sign as the following expression:

$$
\begin{array}{r}
\text { (A6) }-f(\hat{D}(L) \mid c) H_{c}^{1}-f_{c}(\hat{D} \mid c) \int_{\hat{D}(L)}^{W+V+L} \\
{[W+V+L-D] f_{c}(D \mid c) d D .}
\end{array}
$$

As $L \rightarrow 0, \hat{D}(L) \rightarrow W+V+L$. Therefore, since $H_{c}^{1}<0$, it follows from (A4) that:

$$
\left.\frac{d c}{d L}\right|_{L=0} \stackrel{s}{=} H_{L}^{2} H_{\hat{D}}^{1}-H_{L}^{1} H_{\hat{D}}^{2} .
$$

It follows from (A5) and from differentiation of (A2) and (A3) that the expression in (A7) is of the same sign as: 
(A8)

$$
F_{c}(V+W \mid c)-\frac{f_{c}(V+W \mid c)}{f(V+W \mid c)}
$$

Notice that $F_{c}(0 \mid c)=0$, and that $f_{c}(0 \mid c)>0$ under the maintained assumptions. Also notice that as $V+W \rightarrow \tilde{D}, \frac{f_{c}(V+W \mid c)}{f(V+W \mid c)} \rightarrow 0$ while $F_{c}(V+W \mid c)$ is bounded strictly above zero. Therefore, since the maintained assumptions imply that $F_{c}(D \mid c)$ is strictly increasing in $D$ and $\frac{f_{c}(D \mid c)}{f(D \mid c)}$ is strictly decreasing in $D$, it follows from (A8) that there exists a $\tilde{D}^{\prime}<\tilde{D}$ such that

$$
\left.\frac{d c}{d L}\right|_{L=0} \gtreqless 0 \text { as } V+W \gtreqless \tilde{D}^{\prime} .
$$

(A9) implies that $L>0$ at the solution to $[P]$ whenever $V+W>\tilde{D}^{\prime}$.

\section{REFERENCES}

Balkenborg, Dieter. "How Liable Should a Lender Be? The Case of Judgment-Proof Firms and Environmental Risk: Comment." American Economic Review, June 2001, 91(3), pp. 731-38.

Barr, Lewis. "CERCLA Made Simple: An Anal$y$ sis of the Cases Under the Comprehensive Environmental Response, Compensation and
Liability Act of 1980." Business Lawyer, May 1990, 45, pp. 923-1001.

Boyer, Marcel and Laffont, Jean-Jacques. "Environmental Risks and Bank Liability." European Economic Review, August 1997, 41(8), pp. 1427-59.

Lewis, Tracy R. and Sappington, David E. M. "Using Decoupling and Deep Pockets to Mitigate Judgment-Proof Problems." International Review of Law and Economics, June 1999, 19(2), pp. 275-93.

Milgrom, Paul R. "Good News and Bad News: Representation Theorems and Applications." Bell Journal of Economics, Autumn 1981, 12(2), pp. 380-91.

Pitchford, Rohan. "How Liable Should a Lender Be? The Case of Judgment-Proof Firms and Environmental Risk." American Economic Review, December 1995, 85(5), pp. 1171-86.

Rogerson, William P. "The First-Order Approach to Principal-Agent Problems." Econometrica, November 1985, 53(6), pp. 135767.

Shavell, Steven. "The Judgment Proof Problem." International Review of Law and Economics, June 1986, 6(1), pp. 45-58.

Economic analysis of accident law. Cambridge, MA: Harvard University Press, 1987.

Strasser, Kurt and Rodosevich, Denise. "Seeing the Forest for the Trees in CERCLA Liability." Yale Journal on Regulation, Summer 1993, 10(2), pp. 493-560. 